\title{
PERDIDOS NA FLORESTA
}

Eduardo Nadalin ${ }^{1}$

Pergunte a qualquer aluno de francês quais são as impressões dele sobre o grau de dificuldade de aprender essa língua e você tem uma chance considerável de ouvir uma série de queixumes sobre a complexidade do sistema verbal francês, com seus vários tempos e respectivas terminações que parecem se confundir (como se em português isso não ocorresse!). De fato, essa também é uma das preocupações dos autores de materiais didáticos para o ensino de FLE2, o que pode ser facilmente constatado observando-se qualquer manual de francês. Semelhantemente, os professores de francês, na tentativa de tornar esse "complexo" sistema verbal mais digerível, inventam mil e uma atividades. Como professor de francês, eu não sou exceção e vivo tendo idéias "brilhantes" a respeito. Algumas funcionam com alguns grupos, outras não funcionam com nenhum, mas uma dessas idéias, especificamente, surtiu um efeito que considero interessante e que, no meu ponto de vista, pode eventualmente ajudar outros professores de línguas.

Justamente, uma das dificuldades dos alunos de FLE consiste em assimilar a relação entre o passé composé e o imparfait do francês, tempos esses cujos valores correspondem, grosso modo, àqueles do pretérito perfeito e do pretérito imperfeito do português, respectivamente. Em princípio, tudo parece muito simples, pois a relação existente entre os dois tempos verbais do francês e os seus "equivalentes" em português freqüentemente parece ser a mesma. Assim, basta dizer isso aos alunos, treinar um pouco a forma e, c'est fini, vamos tratar de outro assunto.

Obviamente, a coisa não é tão simples assim, ainda mais se considerarmos que os alunos não pensam sobre a relação entre os tempos verbais do português; eles falam a sua língua materna, mas não pensam sobre ela, muito menos sobre partes dela, como é o caso dos tempos verbais acima mencionados. Se eles não refletem sobre a língua que falam todos os dias, é inútil dizer-lhes que o francês tem, em certos casos, um

\footnotetext{
${ }^{1}$ Eduardo Nadalin é Mestre em Letras e Professor de Área de Francês do Departamento de Letras Estrangeiras Modernas da UFPR

${ }^{2}$ Francês como língua estrangeira.
} 
funcionamento semelhante ao do português. Mas por que eles não refletem sobre tais questões? E será que esse tipo de reflexão tem alguma utilidade na aula de língua estrangeira? A experiência que vou relatar talvez indique que alguns alunos refletem sim sobre a língua, materna ou estrangeira. E mais, fazem uso dessas reflexões na tentativa de melhorar seu desempenho lingüístico. E mais ainda, descobrem coisas sobre sua língua materna, desenvolvendo um interesse pelo assunto. Desse modo, ouso afirmar: sim, reflexões sobre a língua podem ser úteis em sala de aula (e eventualmente fora dela também).

Com isso em mente, passo a apresentar, a partir daqui, um relato que consiste em uma série de experiências de sala de aula, todas em torno de atividades que foram se reconfigurando ao longo do tempo, em função das reações e contribuições dos alunos, e cujo objetivo era o de levar os alunos a assimilarem a relação entre passé composé e imparfait. A minha reflexão a respeito iniciou-se justamente a partir das abordagens presentes nos livros didáticos de FLE. Esses freqüentemente utilizam-se do seguinte procedimento para tratar da relação entre os dois tempos verbais em questão: num primeiro momento, exploram os valores e formas do passé composé; em seguida, e em geral separadamente, apresentam os valores e formas do imparfait. Finalmente, ambos os tempos verbais aparecem juntos, e é então que se trata da relação entre eles.

O tratamento dado à relação em questão também é muito parecido nos livros de FLE em geral: parte-se de um documento em que se trata de algum(ns) evento(s) passado(s); em seguida, propõem-se atividades (discussão, perguntas, etc...) sobre o tema apresentado, visando, principalmente, levar o aluno a estabelecer possíveis interpretações do(s) discurso(s) constante(s) naquele documento, de modo que ele perceba que se trata de uma narrativa; por fim, apresentam-se os diversos valores do passé composé e do imparfait, às vezes por meio de tabelas, como em (1) abaixo, com uma certa variação de livro para livro.

\begin{tabular}{|c|c|c|}
\hline \multicolumn{2}{|c|}{ Passé Composé } & \multicolumn{1}{c|}{ Imparfait } \\
\hline$\checkmark \quad$ Exprime as ações da narrativa; & $\checkmark \begin{array}{l}\text { Exprime a situação e o cenário da } \\
\text { narrativa; }\end{array}$ \\
\hline $\begin{array}{l}\text { Relata os eventos principais da } \\
\text { narrativa; }\end{array}$ & $\checkmark \begin{array}{l}\text { Relata os eventos complementares da } \\
\text { narrativa; }\end{array}$ \\
\hline
\end{tabular}




\begin{tabular}{|l|l|l|l|}
\hline$\checkmark$ & $\begin{array}{l}\text { Refere-se a um momento } \\
\text { determinado do passado; }\end{array}$ & $\checkmark$ & $\begin{array}{l}\text { Refere-se a circunstâncias ou a } \\
\text { hábitos passados; }\end{array}$ \\
\hline$\checkmark$ & Exprime um evento acabado; & $\checkmark$ & $\begin{array}{l}\text { Não informa se o evento acabou ou } \\
\text { não; }\end{array}$ \\
\hline
\end{tabular}

As gramáticas de francês, tanto aquelas concebidas para falantes nativos quanto as de FLE, apresentam a relação entre esses dois tempos verbais mais ou menos nos mesmos termos.

O problema com esse tipo de classificação é que os alunos, e por vezes eu mesmo, não conseguíamos perceber de forma clara o que poderiam ser os "eventos principais" e/ou os "eventos complementares" de uma dada narrativa, ou pelo menos havia diferentes opiniões a respeito. Igualmente, a freqüente divergência de ponto de vista quanto ao que seriam exatamente "momento" e "circunstância", ou a constatação de que o passé composé pode também ter um valor habitual - e não apenas o imparfait - acabavam por nos desiludir a todos, professor e alunos, quanto à eficácia de uma tal classificação. Resultado: frustração! Diante desse problema, e pesquisando aqui e ali, "tive" a idéia de alterar um pouco as atividades propostas pelos livros didáticos. Passei então a utilizá-las apenas como uma forma de abordar a relação entre os dois tempos verbais, para depois, com outras atividades, explorar essa questão de forma mais "consistente". Na realidade, o que pensei foi que os alunos não conseguiam associar de modo satisfatório os dois tempos verbais e seus respectivos valores porque eles não eram os autores da narrativa que o livro didático trazia. Em outras palavras, se em vez classificar a narrativa dos outros, os alunos o fizessem com a sua própria narrativa, talvez fosse mais fácil estabelecer o que era "momento" ou "circunstância", o que era "hábito", ou ainda o que era "principal" ou "complementar". E assim propus a eles atividades como (2) e (3a), (3b):

(2) discuta com um colega sobre um acontecimento importante do seu passado. Precise onde você estava, com quem, o que fazia, como você se sentia antes do acontecimento em questão. Em seguida, conte o que aconteceu, diga como você reagiu e como se sentiu depois. Empregue o passé composé ou o imparfait conforme o caso. Após ter contado a sua história e ouvido a do seu colega, escolham juntos a melhor das duas e contem-na para a classe toda. 
(3a) em grupos de 3, observem atentamente esta imagem ${ }^{3}$. O que é? Que pensamentos e sensações essa imagem evoca? Por quê? Discutam em grupo e, em seguida, apresentem as suas considerações para a classe toda.

(3b) em grupos de 3, escrevam uma história a partir desta imagem. Pensem no que pode ter acontecido antes, durante e após a cena retratada. Procurem utilizar o passé composé e o imparfait e tentem situar a sua história no tempo, com o uso de datas e advérbios.

Após todos os grupos terem apresentado as suas histórias, eu lhes propunha que discutissem e completassem um quadro semelhante a (4) abaixo:

(4)

\begin{tabular}{|l|l|l|}
\hline Que tempo(s) verbal(is) foi(ram) utilizado(s) para: & $\begin{array}{c}\text { Passé } \\
\text { composé }\end{array}$ & Imparfait \\
\hline Exprimir as ações da narrativa? & & \\
\hline Relatar os eventos principais da narrativa? & & \\
\hline Referir-se a um momento determinado do passado? & & \\
\hline Exprimir um evento acabado? & & \\
\hline Exprimir a situação e o cenário da narrativa? & & \\
\hline Relatar os eventos complementares da narrativa? & & \\
\hline Referir-se a circunstâncias passadas? & & \\
\hline Referir-se a um evento sem informar se ele acabou ou não? & & \\
\hline Referir-se a um hábito passado? & & \\
\hline
\end{tabular}

Como se pode ver por esse quadro, a única diferença com relação às atividades propostas pelo livro didático era o fato de que a associação entre os dois tempos verbais e seus possíveis valores era feita a partir de uma narrativa criada pelos próprios alunos, e não por uma narrativa previamente estabelecida no material didático. Eu continuava, porém, fiel às tabelas dos livros e gramáticas de FLE. Obviamente, os alunos não estavam nem um pouco preocupados com a minha fidelidade aos livros e subvertiam a tabela sem constrangimento algum. Na realidade, ainda que a variedade de interpretações da tabela tenha diminuído consideravelmente nesse tipo de atividade, o que mudou de forma significativa com relação às atividades propostas nos livros didáticos foi o fato de os alunos defenderem com muito mais convicção a interpretação deles quanto aos possíveis valores dos tempos verbais trabalhados.

\footnotetext{
${ }^{3}$ No caso, uma reprodução da tela de Théodore Géricault, Le Radeau de la Méduse, vide site $<$ http://lettres.ac-rouen.fr/louvre/romanti/medus.html>
} 
Diante dessa situação, decidi tomar uma atitude radical e simplesmente abandonei as tais tabelas. Achava que tinha finalmente encontrado uma solução interessante para a questão, até porque alguns alunos achavam difícil e enfadonha essa atividade. Qual minha surpresa quando um grupo de alunos, após ter realizado as atividades (2) e (3a), (3b) descritas mais acima, e provavelmente influenciados pelo livro didático, pediu para que eu "corrigisse" uma classificação feita por eles, sem que eu a tivesse solicitado. A atitude desses alunos acabou influenciando a maioria do grupo e eu senti a necessidade de "ressuscitar" a prática da classificação que havia abandonado. A essa altura, no entanto, dei mais espaço para que os alunos expressassem o seu ponto de vista e eventualmente propusessem outras classificações que não aquelas já estabelecidas nos livros.

Iniciou-se uma discussão interessante sobre o assunto em que a grande maioria dos alunos se envolveu (alguns apaixonadamente!) e esboçou-se uma classificação feita em conjunto. Nessa classificação, além de considerar os valores dos dois tempos verbais dados no material didático, os próprios alunos observaram que verbos como "pintar" e "saber", por exemplo, quando ocorrem no pretérito perfeito, parecem ter um comportamento diferente ${ }^{4}$. Chegamos a um consenso no sentido de considerar que, num acontecimento como 'Géricault pintou esse quadro', é possível perceber um processo de pintar que resultou na existência de um quadro, ou seja, 'pintou um quadro' como que orienta o nosso "olhar" para o fim do acontecimento em questão. Por outro lado, num acontecimento como "naquele instante, ele soube de toda a verdade', o nosso "olhar" dirige-se não mais para o fim, mas para o momento em que o estado de saber se configurou, ou seja, o início desse estado ${ }^{5}$. Resumindo, o efeito do emprego do pretérito perfeito varia conforme o verbo. Interessante, não?

Essas experiências me levaram a desenvolver três crenças que gostaria de comentar para concluir este breve relato. Em primeiro lugar, parece-me cada vez mais verdadeiro o fato de que é preciso questionar e relativizar o material didático, e não simplesmente aceitar o que ele coloca como definitivo. Além disso, é importante ouvir realmente o que os alunos têm a dizer, e não simplesmente fingir que se ouve para que

\footnotetext{
${ }^{4}$ Cito os verbos em português, mas o mesmo vale para seus equivalentes em francês, respectivamente, peindre e savoir.

${ }^{5}$ Obviamente, é preciso considerar todas as implicações contextuais.
} 
eles se sintam valorizados, mas fazendo prevalecer o nosso ponto de vista, que muito freqüentemente é o do autor do livro didático, a quem não ousamos contradizer. Finalmente, gostaria de fazer algumas considerações sobre a minha terceira crença (provisória), a que trata do papel que podem ter as ditas classificações, tão presentes neste relato, para o ensino de línguas. Considero importante falar do assunto porque, como observei, eu mesmo abandonei quase que por completo esse tipo de procedimento num dado momento, tendo voltado atrás posteriormente.

Para tentar expor meu ponto de vista a respeito, vou servir-me de uma metáfora: imaginemos que aprender uma língua - penso no processo de alfabetização e leiturização em

língua materna também - seja como se ver, repentinamente, em uma imensa e densa floresta, na qual não temos nenhum senso de direção, onde a luz do sol é pouca e onde sabemos haver inúmeros obstáculos e perigos. Ora, se nos encontrarmos num tal ambiente munidos de um mapa e de uma bússola, teremos mais chances de percorrer essa floresta, e chegar a algum lugar seguro, do que se estivermos de mãos vazias. Justamente, penso que as classificações lingüísticas, especificamente, e o estudo da gramática num sentido mais amplo servem para o ensino/aprendizagem de línguas, assim como o mapa e a bússola servem para caminhar com mais segurança (ainda que aparente) na floresta. Obviamente, é preciso lembrar que o mapa não é a floresta e que existem muitos caminhos que ele não mostra. Mas ele pode se revelar muito útil e pode ser aperfeiçoado também. A sua utilidade e o seu aperfeiçoamento, porém, só podem ser efetivamente verificados se o usarmos na floresta, pelo que descartá-lo simplesmente talvez não seja a melhor das idéias. Do mesmo modo, entendo que as classificações lingüísticas e as descrições gramaticais não são exatas, elas não são a língua, mas nem por isso devemos desconsiderá-las. Creio que devemos aprender e ensinar nossos alunos a usá-las, assim como se aprende a usar um mapa e uma bússola, e explorá-las ao máximo, como recursos para que nos sintamos menos perdidos na floresta.

\section{Referências:}


BÉRARD, É., LAVENNE, C.. Grammaire utile du français. Paris: HATIER Didier, 1991. p. 167-174.

BÉRARD, É., CANIER, Y., LAVENNE, C.. Tempo 1 Méthode de français. Paris: Didier, 1996. p. 175.

CAMPÀ, À. et al.. Fórum 1 Méthode de français. Paris: Hachette, 2001. p. 100-101, 204.

CHARAUDEAU, P. Grammaire du sens et de l'expression. Paris: Hachette, 1992. p. 443-492.

POISSON-QUINTON, S., MIMRAN, R., MAHÉO-LE COADIC, M.. Grammaire expliquée du français. Tours: CLE International, 2002. p. 106-109. 